\title{
Adoption of Information Technology for Safeguarding Intangible Cultural Heritage by Cultural Institutions - A Luxury or a Necessity - A Case of Western-Uganda
}

\author{
Alinaitwe Stephen
}

Mountains of the Moon University

DOI:10.36348/SJET.2019.v04i09.006

| Received: 07.09.2019 | Accepted: 14.09.2019 | Published: 29.09.2019

*Corresponding author: Alinaitwe Stephen

\section{Abstract}

This paper focused on information technology (IT) adoption among Cultural institutions in Western Uganda. It was aimed at identifying academic based references to information technologies that plays a role in safeguarding of Intangible Cultural Heritage (ICH), assessing the status of IT adoption by the cultural institutions and providing suggestions to stakeholders in culture on improving information technologies adoption in safeguarding ICH. IT technologies were grouped into two; online and offline based technologies. An examination on primary data collected using interviews and questionnaires revealed that adoption of these technologies is determined by I.T human resource, I.T knowledge of the users and resource base of the cultural institutions. In order to achieve full adoption of IT, There should be a right mix of offline as processing tools and online as dissemination and archiving tool; hiring and retain professional I.T human resources and increasing on I.T budgets. The paper concluded that without a right mix of all these aspects, I.T adoption as a driver of safeguarding measures of ICH remains can only remain dream for stakeholders in Culture.

Keywords: Information Technology, Adoption, Safeguarding Measures, Intangible Cultural Heritage, Custodians, Bearers, Practitioners.

Copyright @ 2019: This is an open-access article distributed under the terms of the Creative Commons Attribution license which permits unrestricted
use, distribution, and reproduction in any medium for non-commercial use (NonCommercial, or CC-BY-NC) provided the original author and source
are credited.

\section{INTRODUCTION}

World development is rapidly introducing new schemes of knowledge capturing and information storage, sharing and communication technologies that deal with information generally termed as Information technologies[1]. These technologies normally leave behind the communities' knowledge and information in Intangible Cultural Heritage, which is often in oral form[2]. Despite the existence of many offline and online communication equipment and applications domains such as websites, online computing infrastructure, and social media platforms where people often interact, these domains have limited content on $\mathrm{ICH}$ [3]. This is often the basis of the threat of intangible cultural heritage. Today, mechanisms for world's knowledge and information storage, sharing and communicating is swiftly shifting to print media, electronic media and internet and associated digital gadgets like DVDs, flash disks and memory cards, cloud computing and artificial intelligence powered systems [2]. If the intangible cultural heritage of the community is not adaptable to these IT platforms due to their limited adoption by the custodians of $\mathrm{ICH}$, then it is disappearing on the world scene. Simply put, if the past cannot be put on these platforms, then it is disconnected from the current and future generations. With instantaneous communications, knowledge and culture can be shared around the world simultaneously. Accordingly; exploitation of I.T creates networked economy[5]- a factor in increasing effectiveness of cultural/ traditional institutions where custodians, bearers and practitioners, are linked seamlessly to share information in real time advancing and embracing the concept of globalization that provides for weakening of cultural barriers and promoting cultural tourism through a technology mix. However, it's worth noting by all stakeholders in safeguarding of ICH that as the world becomes more interconnected, many different cultures come into contact and communities start losing important elements of their ICH through this mix. This calls for appropriate mechanisms [7] for adopting this mix. Otherwise, it affects the young generation who find it more and more difficult to maintain the connection with their treasured elders' ICH that is not represented in this mix. For example, Empaako Naming system among the people of ancient Bunyoro-Kitara kingdom in western Uganda which dates back as early as $15^{\text {th }}$ Century [8] was inscribed on the world list of 
intangible cultural heritage in need of urgent safeguarding by UNESCO in 2013, after a research conducted by Engabu $\mathrm{Za}$ Tooro that is now implementing a UNESCO funded project to document and revitalize ceremonies and practices associated with Empaako naming system in western Uganda, found out the causes of its disappearing as diminishing performance of rituals due to loss of knowledge and information of the ceremonies in the wake of Information technologies[9] like social media and web based communication platforms which are devoid of information about this Empaako naming system [10]. All the proposed interventions (safeguarding measures) to avert the situation are intertwined with Information Technology as the enabler. Such safeguarding measures include Documentation, research, awareness rising and transmission[9]. So taking Empaako naming system as an example, one can argue that if Information Technology was adopted by custodians and ICH adapts to information technology platforms, the status of the viability of Empaako naming system would not have reached a level of disappearance[11].

Adoption of Information technology is considered imperative in aiding transmission of historical memory from generation to generation by the culture practitioners, bearers and custodians since [12] it bridges the gap between the past and the present through targeted educational activities, museums, galleries, exhibition halls, online communities and archives. IT creates opportunities for transitions of "old" knowledge to our "modern times". Cultural based online communities/forums, electronic galleries, archives, depositories and libraries have been created with a goal to expand into the digital era [13]. To this end, the expansion of e-literature and web based bibliographic data has increased awareness and accessibility of ICH materials [4].

In Uganda today, some custodians; cultural researchers, practitioners, bearers that strive to play a role in collecting, storage and exhibiting artworks and cultural artifacts, are in undeviating need of improving on safeguarding their ICH for the future generation and are willing to embrace any support to this end[14]. This is accelerated by their realization of the need to promote their relevance in the national economic and social development within the legal and policy frameworks.

By design and function, traditional/cultural institutions including kingdoms, associations, trusts, chiefdoms, clans, family and some individuals are regarded as custodians of people's identity and mobilization apparatus for development agendas [23] who can be Bearers, custodians or Practitioners. Safeguarding of intangible cultural heritage involves all of these categories of players appreciating the existing Information Technologies on market and acquiring relevant skills for their adoption in safeguarding their culture.
This paper aimed at critically identifying the existing relevant Information technologies available for adoption to safeguard $\mathrm{ICH}$, obtaining the status of IT adoption and suggesting how Custodians, practitioners and Bearers can best adopt these technologies in documentation, awareness rising, transmission and research to preserve and project ICH to posterity. The paper presents an analysis of literature on IT adoption in the context of safeguarding ICH using western Uganda as a case. The discussion based on the results from the study present the way forward on matters related to IT adoption in ICH safeguarding by custodians.

\section{OBJECTIVES}

- To identify academic based references to information technologies that plays a role in safeguarding of Intangible Cultural Heritage.

- To assess the status of Information technologies adoption by the cultural institutions.

- To provide suggestions to stakeholders in culture on improving information technologies adoption in safeguarding $\mathrm{ICH}$.

\section{LITERATURE REVIEW}

This section provides the existing literature on the concepts of Information Technology adoption as an enabler of ICH safeguarding measures such as documentation, research, awareness rising and transmission of Intangible cultural heritage. It helps in the conceptualization of the topic under study that leads to conclusions and suggestions in this paper.

\section{Relationship between IT, Culture and ICH}

$\mathrm{ICH}$ is a defined as the practices, representations, expressions, knowledge and skills as well as instruments, objects, artifacts and cultural spaces associated therewith, that communities, groups and in some cases individuals, recognize as part of their cultural heritage. ICH is made up of elements as complete units and therefore cultural process with a beginning and end[15].

Culture and technology are inseparable, not even in principle. Thus, there is no technology-free culture and separating the two would necessitate undoing human cultures[16]. Certainly contemporary cultures in all parts of the world would not be the same if electricity, automobiles, airplanes, nuclear energy, television and above all, information technology did not exist. One could safely argue that if information technologies in our world vanished suddenly, contemporary civilization would fall into a chaotic state.

Culture means the whole complex of traditional behavior which has been developed by the human race and is successively learned by each generation[7]. It is socially transmitted knowledge and behavior shared by some group of people or individuals 
categorized into three; Bearers-who are the natural descendants of a cultural heritage element and who automatically inherit it, carries it, and thus diffuses it between societies; Practitioners who are individuals or categories of people with specialized roles in transmission and enactment of a heritage and lastly, Custodians who hold in trust, the aspects and values of a heritage on behalf of the bearers as ultimate points of reference.

The United Nations 2030 Agenda for Sustainable Development, which was adopted in 2015, acknowledges culture as an enabler for sustainable development and mutual understanding since it's a collection of treasures[15]. There is need therefore, to take responsibility of leaving these treasures to the next generations as well as displaying them to the present bearers and practitioners who can be tourists. Using ITenabled approaches[7] facilitates increase in awareness of the importance of intangible cultural heritage and hence guarantying the future of cultural heritage. Consistent adoption and integration of traditional and modern Information Technologies leads to the efficient use of ICH data that is very important for saving the cultural heritage let alone Intangible Cultural Heritage (ICH). Generally in Uganda, and specifically in Western Uganda[17], the rate of adoption of advanced IT is still low since in most corridors of ICH custody, spending money on IT is still regarded as a luxury other than a necessity[14]

\section{Safeguarding of Intangible Cultural Heritage}

Safeguarding is associated with ensuring the viability of an ICH element, while preserving its values. In essence, it is about ensuring transfer and communication of knowledge, skills practices, representations, expressions associated with an $\mathrm{ICH}$ from generation to generation through 12 measures; documentation, rising awareness, research, transmission, capacity Building, revitalization, preservation, promotion, protection, enhancement, identification and inventorying (2003 UNESCO convention basic texts). These safeguarding measures can be achieved through traditional and modern forms, formal and non-formal education. ICH being a critical player and an enabler for sustainable development and mutual understanding, UNESCO is promoting it through establishment of conventions such as 2003 and 2005 which are available for ratification by countries as a precursor for state parties to acquire the necessary technical and financial support to safeguard their Intangible Cultural Heritage. This support can be given to individuals, local, national and international Nongovernmental organizations from state parties who are signatories to the conventions. Bearers, custodians and practitioners from the state parties can only safeguard their ICH within the boundaries and prescriptions provided for in the convention. For example, Engabu $\mathrm{Za}$ Tooro, as a contracting organization on behalf of Uganda government as state party to the 2003
UNESCO convention, is currently implementing a 2 year project co-funded by UNESCO to safeguard Empaako Heritage through documenting and revitalization of the practices and ceremonies associated with Empaako naming system among Empaako communities in western Uganda. In the context of this paper, safeguarding was based on 4 out of the 12 safeguarding measures as defined by UNESCO. These are Documentation of ICH element - which is the capturing recording and packaging information on a subject for easy and effective storage and sharing; Research- This is a scientific investigation and exploration of forms, social, cultural and economic functions, modes of transmission, artistic and aesthetic features, history and dynamics of creation and recreation of an element or group of elements of intangible cultural heritage. Awareness rising- is encouraging of the understanding, appreciation and recognition of the value of $\mathrm{ICH}$ and generating respect for it and its practitioners and Transmission - a process of giving of knowledge and skills related to a particular element or ICH in general, in a formal or informal arrangement. Through these methods, ICH education for instance, can be part of school curriculum and seminars, theatres and workshops to pass on knowledge and skills about an element of intangible cultural heritage.

\section{Adoption in Cultural Institutions and Safeguarding of ICH}

In developed nations, most Cultural or traditional institutions engage in production and consumption of art and culture through using a mix of modern and traditional means to communicate and hence forming a bond with IT applications[12]. However, Knowledge and artifacts associated with cultural activities such as dancing, music, theatre, poetry, literature, painting among others need to blend well with Information technology for steady and continuous transmission of this knowledge and skills from generation to generation[7]. This Knowledge can be present in tacit form-the knowledge stored in the human mind as well as in explicit form - the knowledge which is stored in files, records and other types of media [18].

Knowledge about ICH is mostly presented in tacit form posing a danger and risk of disappearing since the youth who are majority in today's population world over comprise the biggest population on online communications platforms like social media that is devoid of this tacit knowledge[19]. Elders- who provide custodial roles in most communities are on traditional media like radio and snail mail. This is a big dilemma [20]for stakeholders in ICH safeguarding to achieve intergenerational communication where the old who have the knowledge and skills about particular ICH elements are glued to traditional media like radio while the youths who need this knowledge are glued to virtual and internet enabled communication channels. There is 
urgent need for cultural institutions to prepare their intangible cultural heritage and associated rich knowledge into formats compatible with both offline and online information technologies. In Uganda most cultural institutions[21] at least have adopted websites and facebook pages but these are not adequately populated with relevant material to attract and occupy the bearers and practitioners who are majority youth spread all over the world. Institutions have not fully exploited the opportunities that come with existing and in most cases free internet based applications like flick, audio farm and Youtube as instruments of $\mathrm{ICH}$ data collection, processing, dissemination, storage and archiving. However, there is thirst for this holistic adoption across many cultural/ traditional institutions[22]. Owing to this, Cultural practitioners, Sponsors, Statutory bodies and government need interventions to put safeguarding of ICH initiatives to another level. Such initiatives include supporting and encouraging the adoption of IT in safeguarding ICH among custodians, bearers and practitioners[23]. An NGO in Western Uganda specializing in promoting Culture, Engabu Za Tooro (Tooro Youth Platform for Action) which is a accredited to UNESCO to offer advisory services has adopted modern methods of documentation especially the web based applications and positive results are being realized despite challenges associated with effective management of these applications[16]. The aim is to upload ICH on online platforms where the youth spend most of their time. However, few of the organizations who play custodial roles are taking such direction. For example, Koogere foundation- a local cultural Community based organization operating in Rwenzori sub-region, Empagi $\mathrm{Za}$ Bunyoro operating in Bunyoro region in western Uganda finds no justification in allocating its meager resources towards creating online communication platforms to advertise its services due to the associated costs of installation and maintenance but take cognizance of the relevance of a computer and a printer to run office duties[24].

Offline and online based information technologies are in the public domain for enabling ICH safeguarding measures as suggested by the UNESCO 2003 convention. Such technologies play a leading role in collecting data about ICH elements and artifacts, processing it to generate meaningful information, dissemination, storage and archiving for intergenerational communication and ultimate projection for posterity[25]. Such applications include: Websites, Audiofarm, Flickr, Blog, social media like Facebook, Twitter, Youtube among others. Information about an ICH element can be exchanged on these online platforms by the help of information technologies among others, multimedia terminals, computers, mobile phones, CD/DVD-ROMs, iPods and flash disks. However, effective adoption of these Information technologies requires coherent skills and the expertise of the administrators and end-users[16]. This paper clusters I.T adoption to safeguard ICH into two; offline tools; online based tools all of which must be supported by relevant and skilled and experienced I.T human resource.

Successful IT adoption within the realm of safeguarding culture requires the bearers, custodians and practitioners in individual or institutional capacity to be aware of the existing technologies and get acquainted with how best to adopt and adapt them into documentation, awareness rising, research and transmission[18]. Therefore, given the enormous potential of IT to impact upon safeguarding $\mathrm{ICH}$, it is imperative that factors that influence the success of ICT integration efforts be systematically explored.

\section{Information Technology Human Resources in Culture Programming}

I.T human resources are the staff required to support the development, usage, maintenance and management of the effects of information technology[25]. Cultural programming is associated with small budgets making it difficult to attract and retain skilled and experienced IT staff needed to attain holistic IT adoption given the specialized training associated with the IT profession[26]. This phenomenon is synonymous with developing countries and explains the wide technology gap commonly referred to as digital divide. This gap suggests that the would-be users of technology, lack the necessary skills and capacity to adopt relevant information technologies[27]. Many researchers have identified right attitude and IT skills mix as a key ingredients for the successful adoption and hence diffusion of an innovation for culture promotion and the degree of this adoption determines how easy it becomes to attain viability of an ICH element[15]. This degree is determined by the key players in the culture ecosystem and as such the success or failure of efforts in IT adoption rests on the shoulders of those who control the budget and are responsible for hiring and firing the information technology staff. According to [28], Organizations with quality I.T staff have transited from just using basic offline and online based tools to complex ones and are progressing well with adopting advanced collection, processing, archiving and dissemination tools and multimedia that are powered by artificial intelligence[29]. Because of limited financial opportunities for Information technology staff, there is a high attrition rate of IT experts in Cultural/ traditional institutions leaving behind a pool of semi-skilled and inexperienced IT human resources who may not support holistic adoption of IT by the custodians of ICH. As a remedy, organizations are implored to begin investing to facilitate structured training [30] programmes for the staff and volunteers of the organization. Naturally, organizations are at different state of preparedness and with capacity levels to adopt I.T but with quality staff, this can be leveled. According [20], Many organizations are beginning to recognize the role of their staff 
including IT human resource by sponsoring them for Trips to attend national and international conferences and meetings which is usually seen as a motivation. Internal change champions and coaches are also critical to the successful implementation and diffusion of IT[4]. Besides internal staff, organizations can engage external staff or consultants to complement their internal manpower.

In a nutshell, relevant and experienced Information Technology human resource is noted as one of the most important factors affecting the adoption of IT. Therefore they must be hired and retained at all costs given their central role in attaining the right mix of simple and complex offline and online based technologies[14]. Since many researchers contend that it is easy to adopt and diffuse Information technology among the organization stakeholders if IT staff is experienced and knowledgeable.

\section{Offline Based Tools in Cultural Institutions}

These include all tools that manipulate information without the help of internet to perform tasks. These include; Computer Software tools also called traditional desktop applications[12] or programs used to operate computers and peripheral devices to collect and manipulate information[31]. Such technologies include; office automation software like Microsoft word, Excel, Access of text and figures, Multimedia packages [29] which help users with manipulation of pictures images, sound and videos. Common with these packages, is little or no acquisition costs and maintenance costs since majority are free ware and open source packages- a reason that can explain their high rate of adoption[32]. Worth mentioning is that basic technical know- how among practitioners, bearers and custodians exists. These skills are acquired through short course training conducted by mainstream educational institutions spread all over the country. However[30], in advanced economies, culture is now safeguarded by using artificial intelligence applications particularly in formulating narratives for framing a cultural artifact in the context of the life of the artist, the social and political context in which the work was created. Examples of such artificial intelligence applications include smart personal assistants, such as Siri, Cortana, Google Now and Google assistant. However, in developing countries, the rate of adoption is not all the best but it is promising. Accordingly[2], the more accessible the technology, the more decentralized and potentially utilized it will be.

Hardware tools are physical parts of the computer system that include; Input/Output devices like computers, computer peripheral devices like scanners, keyboard, sound recorders and mobile phones, cameras, printers, plotters and overhead projectors together with their accessories that play a leading role in capturing, processing and presenting information[33]; storage Devices like solid state drives-SSD, Optical and tape drives, USB drives, RAID storage and flash memory cards; Data processing tools such as audio, video and photo processing equipment like cameras[18] and the Computer system Unit. The users of such tools need to have a physical working space with access to electricity since most of them are electronic and thus electrical equipment. They are reliable and most common Information Technologies adopted by Custodians in most Organizations and as such they are considered basic tools required for an individual or community to become digitally enabled[7]. It is unfortunate that the struggle to become I.T compliant in many developing countries [9]ends at attaining this level and yet exploiting the full potential of I.T requires graduating to the use of online based applications or internet enabled tools with an aim to disseminate the knowledge to the masses[18].

In IT adoption, once offline based technologies are available, emphasis should be put on their effect use. Effective utilization of offline tools creates impetus to link to online systems and graduating into adoption of complex offline and online information technologies[13]. This is what is considered as effective IT resource utilization and can be achieved through intranetworking different devices like printers, scanners to facilitate group sharing during job printing and file access through a protocol called File Transfer Protocol (FTP)[6].

\section{Online Based Applications}

Adopting web-based application enables users to work from anywhere anytime[34]. Online based applications are tools that can be accessed from any device by anyone; anywhere as long that device is connected to the internet[4]. Data is available from anywhere after the user logs in thus, providing for; User accessibility via a uniform environment such as the web browser, Increasing interoperability- web applications have the capability of sharing all data with congruent software and Easier to maintain- users have the ability to access the latest updates directly via their online platform, whether it be desktop or mobile device[25]. Online based applications can be categorized into two: -

Communication tools for dissemination of information [35]such as email, Skype and social media platforms such as Facebook, Twitter, Watsapp among others. The arrivals of these channels of communication have revolutionized the world. All sectors are experiencing positives and negative effects arising from the adoption of these systems. Although the youth are increasingly adopting these tools to communicate among themselves, do research and study from their peers and superiors, their uptake rate among the old generations is still low[14]. Much as communication tools make life easy, they have some challenges as well. For example, emails on company domain help to identify communications with the sender but they are not easy to access and not reliable since they depend on 
availability of the company domain name as compared to free emails on global communication systems like gmail and yahoomail among others[12].

Archiving tools such as flickr, Youtube, audio farm, Website, Blog, web portals; online forums and online communities are also increasingly being used as storage and repository tools[2]. Through such media, ebooks, e-family/community libraries and museums can be constructed, accessed and maintained for generations. However, users complain of time wasting and bandwidth consumption as challenges hindering their effective use. In developed countries, Cloud computing applications like idrive, amazon dropbox, google cloud platform and OneDrive are on the sharp increase and are relied upon to offer data, information and knowledge management services because they offer secure and sustainable archiving services as depositories of information[20]. This is not the case in developing countries due to the digital divide. In addition, for some Cultural artifacts and spaces that are considered sacred may not be put on these platforms for fear of undermining the respect attached to them by non-bearers[1]. This suggests the stringent and slow absorption rate of such systems as drivers of safeguarding ICH.

Websites are considered not dynamic enough as compared to blogs due to lack of flexibility in uploading an article about an event and the costs associated with their application since they require service fees inform of domain name registration and hosting[36]. Practitioners and bearers frequent Youtube to share videos of their folklore music and dance but are limited by IT expertise and bandwidth requirements[16]. Other challenges that come with online applications are how to ensure data security and establishing trust among the users. Although blogs are preferred to static website because they are usually maintained by an individual with regular entries of commentary, descriptions of events, or other material such as graphics or video, technical know-how is still a challenge to the novice users.

In order to ensure the adoption of archival systems that are flexible[37], legal, secure and compliant to guarantee intergeneration retrieval of relevant data about their heritage, complementary efforts among the players in culture and information technology experts is a must[25]. This is because the task is not easy as it involves resources inform of cash and expertise. During adoption of IT, caution must be put on culture beliefs of the players. The current lack of attention to cultural beliefs and their impact on ICT adoption in especially in developing Countries is an issue highlighted by many researchers[9]. In general terms, making information technology, an essential part of the cultural institutions in developing countries is still a challenge and cannot be attained by simply deploying more computers and their accessories more so in communities with strong cultural beliefs[25]. Force-fitting the culture to the technology can create an unfavorable climate for the adoption and ultimately affect the utilization of IT in different cultural organizations. In fact, unless taken into consideration, socio-cultural factors may put IT adoption at risk[4].

Despite the critics that the revolution of information technologies has led to the loss of cultural values and norms among the youth, the online communication systems has particularly contributed to breaking of Cultural barriers and hence promoting culture tourism championed by the youth.

\section{THE STUDY}

In view of the current state of the literature as presented above, this study explores the adoption of Information technologies in cultural/ traditional institutions. It provides a description of the technologies being utilized and the level of their usage. It explains the adoption status and suggests ways of improvement. Considerations is from the perspective of adoption of offline an online Information technologies by custodians of ICH who are bearers or Practitioners of on implementation, documentation, research, awareness rising and transmission of ICH. Findings from the empirical questions and arguments are provided to support the anticipated results.

\section{METHODOLOGY}

A case study research design was deployed using Semi-formal face to face interviews and questionnaires to carry out this descriptive study. Case study design's ability to investigate cases in depth and to employ multiple sources of evidence makes it a useful tool for descriptive research studies[38].Owing to its effectiveness in communication between the interviewer and the interviewee, Interviews helped to obtain Information from custodians and in some cases their representatives. The researcher preferred it due to its flexibility in managing the primary data from especially the custodians who were elderly and needed dynamic data collection tools. This approach provides for more spontaneous responses. Purposive sampling was then used to reach the participants in this study[39]. This type of non-probability sampling is about handpicking of cases to be included in the sample on the basis of the researcher's judgment of their typicality .Questionnaires in electronic and hardcopy forms were also used especially to obtain information from youthful practitioners and bearers of $\mathrm{ICH}$.

A cross section of ICH Bearers and practitioners spread across different realm such as; Cultural based NGOs, IT practitioners, Cultural policy advocacy sympathizers, clan heads, ritual leaders, ritual guides, family heads and individuals were randomly selected across different Cultural settings in western Uganda. The study employed a strategy of Stratification in an attempt to accommodate for all the roles in the 
safeguarding of ICH. A total number of 92 respondents were reached via interviews and questionnaires- in hard and softcopy. SPSS package aided the researcher to obtain descriptive analysis using regression tables, bar charts plus other appropriate forms of output presentations.

Table-1: Number of Respondents per category of players in ICH safeguarding

\begin{tabular}{|l|l|l|l|}
\hline No & $\begin{array}{l}\text { Target groups } \\
\text { according to Roles }\end{array}$ & Description & $\begin{array}{l}\text { Number of } \\
\text { respondents }\end{array}$ \\
\hline 1 & Bearers & These are Natural descendants/ owners of ICH. & 49 \\
\hline 2 & Practitioners & $\begin{array}{l}\text { These are Professional with specialized roles in } \\
\text { ICH safeguarding }\end{array}$ & 25 \\
\hline 3 & $\begin{array}{l}\text { Custodians or } \\
\text { representatives }\end{array}$ & $\begin{array}{l}\text { These are People/institutions who hold in trust the } \\
\text { values and aspects of the ICH. }\end{array}$ & 18 \\
\hline
\end{tabular}

\section{RESULTS}

From the 92 respondents targeted, the researcher was able to obtain responses from 83 consisting of $90 \%$ response rate. This is good enough to guarantee accurate results from a case study. Culture being sensitive to youth and women, their participation was paramount. This is a reason for high percentage of the youth at $65 \%$ and women at $58 \%$ as respondents that were included in the study. Bearers constituted the biggest percentage at $53 \%$ since there is no qualification for being a bearer of an ICH element a part from just being natural descendants who were readily available in different cultural communities.
Findings on whether they use Information technology in daily life, $89 \%$ of them indicated that they do send and receive messages and share memories with their friends and family using some form of basic information technologies.

Of those who adopt basic Information technologies, variations were evidenced from one IT adoption category to the next as presented below; $26 \%$ of those $89 \%$ respondents indicated that they use online based technologies like facebook and email to communicate on matters of Culture. $95 \%$ of the $89 \%$ indicated that they adopted the use of some form of hardware tools in the offline category like computers and mobile phones.

\begin{tabular}{|lc|}
\hline & \\
\hline Items & Percentage of 83 respondents \\
\hline & \\
Custodians, bearers, practitioners & \\
Send and receive messages using common I.T tools & $26 \%$ \\
Use Hardware Tools like Computers and mobile phones & $95 \%$ \\
Use online storage, archiving and depositories & $43 \%$ \\
Use cloud computing systems & $16 \%$ \\
Use artificial intelligence systems & $11 \%$ \\
Having relevant skills of using IT & $48 \%$ \\
& \\
& \\
\hline & \\
& \\
ICH Custodians/institutional capacity & $23 \%$ \\
Trained IT human resources & $32 \%$ \\
Permanent and dedicated IT human resources & $29 \%$ \\
Exposure to Information technologies & $28 \%$ \\
Availability of Financial resources & $95 \%$ \\
Recognition of the role of I.T & $35 \%$ \\
Considers IT as a menace to ICH & \\
\hline & \\
\hline
\end{tabular}

From the table 1 above, $43 \%$ of the $89 \%$ IT adopters use storage, archiving and depositories tools like Flickr, blog, audio firm and YouTube. Only 16\% adopted cloud computing applications like drop box and icloud to archive their ICH data. Only 11 percent had adopted artificial intelligence systems like Google assistant. $23 \%$ of custodian institutions had recruited formally trained IT human resource with relevant qualifications in Information technology discipline. $32 \%$ of custodian institutions had permanent and dedicated IT staff to man the information technologies.

Only $29 \%$ of the respondents had exposure to information technologies. $58 \%$ lack the relevant skills 
to use information technologies. $82 \%$ are challenged by limited financial resource envelopes allocated to Information technologies. 95\% recognize the role of IT as Vital and crucial. While $35 \%$ consider IT as a hindrance to $\mathrm{ICH}$ safeguarding.

\section{DISCUSSIONS}

Facts from the study reveal that most institutions take recognition of the need to step up their digital strategy to cop up with the pace of technology advancement. This phenomenon supports [41] who suggests that usually in technology adoption, there is willingness but the challenge is a way. This willingness is across all the three categories of bearers, practitioners and custodians of ICH[6].

The results reveal that most organizations work with inexperienced and unqualified IT staff in addition, technical ability of other organizational staff to use Information technologies is also wanting as shown in table 1 above. For sustainable adoption and eventual diffusion of information Technology as supported by, top management of cultural institutions and practitioners must act as vision bearers and embrace information technology adoption as a master piece at the forefront of promoting culture. High I.T staff attrition is due to meager resources associated with cultural programming may form part of contributing factors for the saturation of inexperienced staff in most cultural based organizations[1]. The remedy of this lies in Non-monetary rewards like donor funded trips to attend international or national meetings and conferences to motivate the staff. Soft and hard skills acquisition by staff through training drive needs to be kept ongoing in addition to adopting strategies for skilled staff retention[21]. The right policies, strategies and legal framework that promote training in short course programmes such as IT essentials and software applications need to be developed and sustainably implemented. If Culture is be developed[3], then it should not only be seen as "a thing of" kingdoms alone but an important ingredient in promoting social cohesion, economic and political development thus all players and partners in development need to advocate for IT adoption as driver for safeguarding ICH.

According to [4], Skilled information Technology professionals need to be hired and retained despite the meager resources in the culture sector through incentives and rewards as argued by [42]. The findings also suggest that appropriate guidelines, policies and legal frameworks regarding IT adoption need to be incorporated in the cultural programming in a top to Bottom approach and vice versa since they have potential to drive national budgets alignment with culture as a driver for industrialization and peace building as claimed by [43].

Findings show that 'basic' Information technologies mostly the offline category are frequently used as shown in the table 1 above. This is due to the simplicity and less costs associated with their use and maintenance.

After all, the skills required to use offline based technologies[26] are readily available since it can be obtained from tertiary, secondary and primary learning centers spread within reach of cultural custodians, bearers and practitioners. On the other hand, Users find themselves with no option but to acquire and learn how to use a computer and phone accessories to deal with information as a survival strategy[33]. Adopting technology is one thing and effectively using it is another altogether. These results suggest that awareness on acquisition and effective adoption of tools like computers and its accessories and relevant software should be emphasized to attain effective use of offline based tools through conducting workshops and seminars. Users need appropriate support to adopt advanced hardware and software systems but it is still difficult for developing countries[9]. The biggest hindrance to adoption of technology either basic or advanced is related to perception, attitudes and beliefs. Confidence and selfesteem can also affect the adoption of a technology. Information captured and processed using offline based systems is half used. The cycle is completed when such information is uploaded on online systems for easy sharing with outside world and eventually archiving for future generations[7]. Caution must be taken to prepare and present information using appropriate formats for different audiences that are linked and connected through online media. This will solely depend on the skills of the users and the quality of the equipment used. Therefore, a right combination of skilled human resource and the quality of the offline technologies is the answer for effective communication[13].

Materials, skill, knowledge and artifacts associated with ICH need to be where the youth are. The youth of today are on online communication systems. This study revealed that web based technologies, mobile applications and archiving tools are frequented by the bearers and practitioners of cultural heritage majority of whom are the youth as compared to the custodians who are adults or elderly members of the community. This is supported by. The results revealed that online based tools are not common among custodians who are still stuck with traditional mechanisms of communication and yet online media like blogs and flickr are the way to go[35]. Website technologies were adopted by most institutions and they seem to have enough knowledge to operate them despite the heavy maintenance costs.

Information associated with cultural materials produced by Offline based tools need to be shared on online systems in different multimedia to suit the different tastes and preferences of audience for easy consumption[21]. Online communities and forums are 
proving effective in transmission of culture[15] and thus need to be emphasized by cultural based institutions.

From the statistics above, not everyone will immediately adopt an idea that seemingly appears distructive despite obvious benefits. Because of fascinating personality traits, people will accept to adopt new innovations in levels but according to [20] Adequate Management support can bring about a segment of technology adoption called Innovators who are the first individuals to adopt an IT innovation and are willing to take risks. They are usually youngest in age, have the highest social class, have great financial lucidity, very social and have close contact to scientific sources and interaction with other innovators [18].

Therefore, it is more probable that cultural institutions with stronger top management support for Information technology adoption would be more likely to adopt such systems since it can provide long-term vision, concepts and adequate support, and the obligation to generate an affirmative atmosphere for the IT adoption as argued by [27].

Lastly, creating, promoting and rewarding champions in Information technology adoption[23] should be top on the agenda of all stakeholders in safeguarding of intangible cultural heritage in order to build a spirit of striving for adoption of the latest and advanced technologies innovatively. Since the Artificial intelligence applications are here to stay and are more likely to replace human space [29], they should be an aspiration of cultural players building on the positive attitude and recognition of the importance of Information technology by the bearers, custodians and practitioners to attain full potential of Information technology benefits.

\section{CONCLUSION}

This study was motivated by the transformation associated with adoption of Information technologies on safeguarding of Intangible cultural Heritage and how best cultural institutions as custodians of culture; bearers as natural descendants of culture and practitioners as professionals with specialized roles; can adopt them in safeguarding their intangible cultural heritage. This paper points out information technologies that are commonly used and those least used. It points out that most custodians and practitioners relatively use offline best technologies like computer hardware and software to do basic activities like typing and printing letters while majority of bearers who are mostly youth, use both tools to communicate, but even then, few of them use advanced tools like artificial intelligence software such as google assistants and cloud based archiving tools like drop box, icloud among others to transmit culture. They have little knowledge on the existence, let alone usage and role of advanced offline based tools and online based applications in promoting culture. As a result, the skills, knowledge and artifacts associated with Intangible Cultural Heritage are detached from effective transmission from generation to generation.

The paper asserts that for effective safeguarding of $\mathrm{ICH}$ there must be intergenerational communication. In other words, if cultural institutions are to effectively safeguard their $\mathrm{ICH}$, then all the three categories of players in ICH safeguarding; Bearers, Custodians and practitioners must understand the role of IT adoption in their activities and strive to acquire relevant skills and resources to adopt this knowledge. This implies that they must procure and install this equipment and strive to be proficient in using the offline based tools both basic and advanced computer hardware and software tools to assist in data collection processing and storage. For example, knowing how to use word processing systems to create letters and documents, spreadsheets for calculations during budgeting, phone cameras for taking photos and recording video clips and sound, and creating, saving and maintaining files on offline storage systems such as disks and discs and advanced offline storage media and collection equipment like RAID and cameras and multimedia systems respectively. In addition, they must learn how to link offline based tools with online based applications for purposes of disseminating and archiving all information and knowledge obtained using offline based tools to a wider population spread all over the world as the only mechanism to facilitate intergenerational communication. Such online systems include web based online communication platforms like websites, web portals, flickr, Youtube, facebook, online communities, blogs, audio farm and cloud computing based systems such as icloud, dropbox, idrive, amazon google cloud platform and OneDrive. More so an attempt to start using communication applications powered by artificial intelligence systems should be their next move. This is because each of the online based tools plays a specific role complementary to each other in dissemination and archiving knowledge and information associated with ICH hence it's safeguarding.

This paper raises some issues of limited capacity of practitioners, bearers and custodians in terms knowledge of the existence of information technologies, skills to use Information technologies; limited financial muscle to acquire the appropriate and install relevant IT equipment and inadequate relevant Information Technology human resources who are experienced. In fact, these factors are linked to meager resources associated with cultural programming.

The paper suggest that these encumbrances can be reduced by attracting more IT human resources who will in turn transfer relevant skills to the stakeholders through routine training and mentoring and coaching hence forming a right mix of information technologies. 
This can be through offering non-monetary incentives and rewards like donor sponsored trips to attend international and national meetings and conferences and continuous advocating for the right policies, legal frameworks and strategies within their local and central governments which will lead to increase in funding for Culture programming.

\section{LIMITATIONS}

Although the paper reveals encouraging results, it is imperative to put into recognition that the current findings also have limitations. First, the sample size should be increased to cover at least $80 \%$ of the all the custodians and practitioners in ICH domain in Uganda because using data from a larger number of respondents will lead to more accurate insights. Second, some participants of this study, especially elderly custodians, bearers and practitioners were interviewed on phone and due to poor network during the interview or even the language barrier might have distorted the Reponses. Thirdly, responses from participants regarding rating their proficiency in using Information Technologies, especially custodians and practitioners might have been over or under rated which could contribute to inaccurate conclusions. However, in spite of these limitations, this study will be useful to policy makers, professionals in culture development programs, information technology fraternity (system developers and managers) funders and promoters of culture at local and international levels.

\section{FUTURE RESEARCH}

Firstly, Bearers, practitioners and custodians relatively use basic online and very few use online based applications due to limited skills among themselves and inadequate relevant and skilled IT human resource and finances to acquire and install information technology equipment. This shows that there might be other factors that affect the adoption of Information technology in safeguarding $\mathrm{ICH}$ which can be understood by carrying out further research.

Secondly, this paper was based on a study on $\mathrm{ICH}$, further studies can widen the scope to include IT adoption on safeguarding both tangible and intangible cultural heritage.

\section{REFERENCES}

1. Touray, A., Salminen, A., \& Mursu, A. (2013). ICT barriers and critical success factors in developing countries. Electronic Journal of Information Systems in Developing Countries, 56(1), 1-17.

2. Guccio, C., Martorana, M. F., Mazza, I., \& Rizzo, I. (2016). Technology and public access to cultural heritage: The Italian experience on ICT for public historical archives. In Cultural Heritage in a Changing World.

3. Maraña, M. (2010). Culture and Development: Evolution and Prospects. UNESCO Etxea, 1, 30.

4. Eneh, O. C. (2010). Technology transfer, adoption and integration: A review. Journal of Applied Sciences.

5. Gruber, M. R. (n.d.). The Role of E-Learning in Arts and Cultural Heritage Education.

6. Im, I., Hong, S., \& Kang, M. S. (2011). An international comparison of technology adoption: Testing the UTAUT model. Information \& management, 48(1), 1-8.

7. Im, I., Hong, S., \& Kang, M. S. (2011b). An international comparison of technology adoption. Information \& Management. https://doi.org/10.1016/j.im.2010.09.001

8. Toz, G., \& Duran, Z. (2004). Documentation and analysis of cultural heritage by photogrametric methods and GIS: A case study Documentation And Analysis Of Cultural Heritage By Photogrametric Methods And Gis : A Case Study. (June), 1-5.

9. Isingoma, B. (2014). Empaako " Praise Names ": An Historical , Sociolinguistic , And Pragmatic Analysis. 35(June), 85-98.

10. Kurin, R. (2004). Safeguarding Intangible Cultural Heritage in the 2003 UNESCO Convention: a critical appraisal. Museum International. https://doi.org/10.1111/j.1350-0775.2004.00459.x

11. Ssewanyana, J. (2007). Adoption and usage of ICT in developing countries: Case of Ugandan firms Michael Busler. 3(3), 49-59.

12. UNESCO. (2016). 2003 Convention Basic Texts 2016.

13. Drigas, A., \& Koukianakis, L. (2010). Convergence of Culture and ICTS: E-Culture. 488-496.

14. Maghrabi, R. O., \& Palvia, P. C. (2012). the Impact of Information Technology (It) on National Culture: the Case of Saudi Arabia. Proceedings of the International Conference on Information Systems (ICIS), 1-11. https://doi.org/10.1061/(ASCE)07339429(2004)130:9(870)

15. Arokiasamy, A. R. A., bin Abdullah, A. G. K., \& Ismail, A. B. (2014). Correlation between cultural perceptions, leadership style and ICT usage by school principals in Malaysia. Turkish Online Journal of Educational Technology, 13(3), 27-40. https://doi.org/10.1016/j.sbspro.2015.01.478

16. Dimitropoulos, K., Manitsaris, S., Tsalakanidou, F., Nikolopoulos, S., Kork, S. Al, Crevierbuchman, L., Yilmaz, E. (n.d.). Capturing the Intangible: An Introduction to the i-Treasures Project.

17. Pineda, R. (2014). Technology in culture: a theoretical discourse on convergence in humantechnology interaction.

18. CCFU. (2008). Culture in development in Uganda.

19. Stuedahl, D., \& Vestergaard, V. (2018). Media Innovations and Design in Cultural Institutions. Stema Specialtryck AB, Borås, Sweden, 2018.

20. Ciganek, A. P., Haseman, W. (Dave), \& Ramamurthy, K. (2014). Time to decision: the 
drivers of innovation adoption decisions. Enterprise Information Systems.

21. Velarde, O., \& Bernete, F. (2015). Paradigms of the impacts of ICT on culture and knowledge. 347380. https://doi.org/10.4185/RLCS-2015-1050en

22. Kaddu, S. (2015). Collaboration in Digitising Cultural Heritage as a strategy to sustain access and sharing of cultural heritage information in Uganda. Library Theory and Research.

23. Ministry of Gender, L. and S. D. (2006). Uganda National Culture Policy (pp. 1-32). pp. 1-32.

24. Ioannidis, Y., Toli, E., El Raheb, K., \& Boile, M. (2014). Using ICT in cultural heritage, bless or mess? Stakeholders' and practitioners' view through the eCultValue project. Lecture Notes in Computer Science (Including Subseries Lecture Notes in Artificial Intelligence and Lecture Notes in Bioinformatics), 8740, 811-818.

25. Expectations and Aspirations (2015-2021) A Statement by Cultural Institutions in Uganda. (2015).

26. Lee, I., Choi, B., Kim, J., \& Hong, S. J. (2007). Culture-technology fit: effects of cultural characteristics on the post-adoption beliefs of mobile internet users. International Journal of Electronic Commerce, 11(4), 11-51.

27. Salinas, Á., Nussbaum, M., Herrera, O., Solarte, M., \& Aldunate, R. (2017). Factors affecting the adoption of information and communication technologies in teaching. Education and Information Technologies, 22(5), 2175-2196.

28. Chong, A. Y. L., Lin, B., Ooi, K. B., \& Raman, M. (2009). Factors affecting the adoption level of ccommerce: An empirical study. Journal of Computer Information Systems, 50(2), 13-22.

29. Ocen, G. (2002). Organisational Implementation of ICT.

30. Artificial Intelligence for Cultural Heritage. (n.d.).

31. Ejiaku, S. A. (2014). Technology adoption: Issues and challenges in information technology adoption in emerging economies. Journal of International Technology and Information Management.

32. Sriwindono, H., \& Yahya, S. (2012). Toward Modeling the Effects of Cultural Dimension on ICT
Acceptance in Indonesia. 65(ICIBSoS), 833-838.

33. Liang, H., \& Xue, Y. (2009). Avoidance of information technology threats: a theoretical perspective. MIS quarterly, 71-90.

34. Munyaradzi, G., Musungwini, S., \& Chitanana, L. D. (2014). The Use Of Information Communication Technology By A-Level Teachers In Selected Secondary Schools In Gweru , Zimbabwe. Researchjounali's Journal of Technology Management, 1(1), 1-21.

35. Powell, T. C., \& Dent-Micallef, A. (1997). Information technology as competitive advantage: The role of human, business, and technology resources. Strategic management journal, 18(5), 375-405.

36. Musa, N., Githeko, J., \& El-Siddig, K. (2013). Challenges of using information and communication technologies to disseminate agricultural information to farmers in Sudan. International Journal of Sudan Research, 3(2), 117-132.

37. Bagchi, K., Cerveny, R., Hart, P., \& Peterson, M. (2003). The influence of national culture in information technology product adoption. Americas Conference on Information Systems (AMCIS).

38. Bryman, A. (2012). Social Research methods (4th ed.). Newyork: Oxford University Press.

39. Etikan, I., Musa, S. A., \& Alkassim, R. S. (2016). Comparison of Convenience Sampling and Purposive Sampling. 5(1), 1-4.

40. Etikan, Ii., \& Bala, K. (2017). Sampling and Sampling Methods. Biometrics \& Biostatistics International Journal, 5(6), 5-7.

41. Bagchi, K., Hart, P., \& Peterson, M. F. (2004). National culture and information technology product adoption. Journal of Global Information Technology Management.

42. Terera, S. R., \& Ngirande, H. (2014). The Impact of Training on Employee Job Satisfaction and Retention among Administrative Staff Members : A Case of a Selected Tertiary Institution. 39(1), 4350.

43. Robinson, K. B. (2016). Handbook on integrating gender in peacebuilding and. (October). 